\title{
Selling the Unfamiliar Knowledge on Architectural Firms
}

\author{
Rashad Al Saed \\ Skyline University, Sharjah, UAE \\ Abedulrahman Al-Juboori \\ Zaytoonah University, Amman, Jordan
}

\begin{abstract}
Whilst it may be challenging to promote a professional firm's traditional architectural services to clients, both existing and anticipated, it is quite another thing to promote the services of an architectural firm that designs, manages, builds, and maintains buildings. This paper presents a case study of a firm that adjusted its service provision and adjusted the way in which it marketed its services over a four year observational period. The paper addresses issues of client resistance and stereotyping against a background of increased competition and shifting professional boundaries. In particular, the case study highlights: (1) the challenge of communicating a firm's culture; (2) the opportunity and limitations of a limited marketing budget; (3) the challenge of communicating change; and (4) the paper concludes with a number of issues for further research and consideration.
\end{abstract}

Keywords: culture change, diffusion of innovations, external communication, professional service firm

\section{Introduction}

It is of little use developing a competitive professional service firm if potential clients are unaware of the services on offer. The challenge for the architect led firm will be to sell services to clients who may well have a fixed view of what an architectural practice can deliver, a view reinforced by other players in the marketplace. Effective promotion, therefore, is essential to the ongoing competitiveness of the organisation. But it is important to recognise that an organisation must "know its business" before any marketing strategy is put in place. More specifically, the firm's culture must have been designed, and its aims, both short term and long term, agreed, before a promotion strategy can be implemented. Three core areas-namely, individual job management, staff management, and client relations - make up the professional service firm's culture. These in turn will influence the type of message given out by the firm to its existing and potential clients, because it is its culture that is being communicated. Advertising, promotion, and marketing are all terms used to cover an organisation's communication with its external environment. They are concerned with sending and receiving messages. With the exception of the highly regarded work of Coxe (1980), there are few books that specifically address the issue of marketing, advertising, and public relations to architectural firms. One of the most comprehensive guides for the architectural profession was published under the title The Marchitect (RIAS, 1990) in which architects were urged to develop a structured approach to attracting and retaining clients. Marketing and communication techniques for architects by Ryness (1992) are provides a wide selection of

Rashad Al Saed, Ph.D., Professor of Marketing, International Business \& Marketing Department, Skyline University. Abedulrahman Al-Juboori, Ph.D., Assistant Professor, Business Department, Zaytoonah University.

Correspondence concerning this article should be addressed to Rashad Al Saed, Skyline University College, City University, P.O. Box 1797, Sharjah, UAE. E-mail: ralsaed@skylineuniversity.com. 
examples drawn from practice. More recently, Richardson's (1996) Marketing for Architects and Engineers offers an alternative approach based on scenario planning and synthesis. Many authors use the generic term marketing to cover all three elements of service promotion. According to Kreps (1990), advertising, marketing, and public relations efforts are complementary and interdependent forms of external communication. It is activity that it should be measured for performance and must be managed to ensure success (Maister, 1993) and an activity at the heart of the competitive professional service firm (Emmitt, 1999).

It is well recognised that professionals are first and foremost concerned with satisfying their clients' needs and are notorious for regarding the running of their business, of which marketing is a fundamental element, as a secondary concern. As such they are often charged with ineffective management, squandering profits and, more importantly, missing opportunities to expand their market share-leading to lower profits and threatening the firm's long-term viability (Maister, 1993). Architectural firms have not escaped from this criticism (RIBA 1992), seemingly ill at ease with the concept that architectural practice is, first and foremost, a business, a business which relies on clients for its survival.

\section{The Communication of the Firm's Culture to Its Clients}

Whatever term is used-be it public relations, marketing or advertising — the process is concerned with communication, the communication of the firm's culture to its clients. Everything an organisation does have a secondary function as promotion. The way in which designs are presented, meetings administered, problems attended to and so on are all part of the marketing initiative because they provide people outside the organisation (both existing and future clients) with information about the firm's approach to every aspect of its business. Marketing to existing clients is often taken for granted by professional firms, yet existing clients represent the most probable source of new business (Maister, 1993). Existing clients need to be nurtured and much of the effort of developing the business around existing clients will be of an interpersonal nature, supported with targeted promotional material. This is especially true where the firm seeks to make the client a cohesive element of the firm's culture, requiring input from the client as well as the firm. Attracting new clients takes a different form of effort, and it is more demanding of resources because many potentially profitable clients may already have an established network of contacts, so the firm must recognise that it will try to dislodge a competitor.

\section{Every Firm Has Its Own Culture}

Every firm has its own culture, either by design or by accident, and therefore each firm has its own corporate image, or corporate identity. Corporate identity is concerned with how the firm is perceived by its clients (existing and prospective), its staff, competing firms, and the public. Perception will be based on experiences of the service provided by the firm, the firm's culture, and the manner in which it presents itself through marketing activities. It is an area often taken for granted by architectural firms, yet, the consistent communication of a corporate image is one way of distinguishing the firm from others offering similar services. The face needs putting to the name.

Graphic communication is the trademark of the architectural firm and both its culture and corporate image are reflected in letters, reports, presentation drawings, detail drawings, and contract documentation as well as the specifically designed marketing material. As part of the corporate image, the standard of graphic communication should be high, but more importantly, consistent. Many firms are aware of the importance of 
corporate identity through their graphic communication, and operate a "house style”. Other firms are less fussy and have an inconsistent (amateur) approach to the material that they produce. They put out a confusing message, one that is often perceived by clients as representative of a poorly managed firm.

Corporate identity should link all firms' activities into one easily identifiable and memorable image (RIAS, 1990). The establishment of a corporate identity takes time and inevitably will change as the firm itself responds to changes in the market. Once a corporate image has been designed and agreed a variety of promotional tools can be employed to raise awareness of the firm amongst existing and prospective clients, ranging from the corporate brochure to newsletters and direct mail campaigns. Promotional tools help to bring the attention of the firm to potential clients and also to reinforce its image with existing clients. Bringing about and raising awareness is particularly important. If a client is unaware of the firm or the firm's range of service provision, it will not be considered. Whatever a firm's individual strategy, it is important to remember the importance of training and continual updating so that the firm's promotional strategies retain their currency. It is one thing to set up and monitor the firms promotional strategies, quite another to maintain the momentum.

\section{The Impact of Change on the Firm}

A well-designed and planned promotional campaign will consider the impact of change on the firm, the service provision and the manner in which it is communicated to clients. As a general rule, it is better to keep clients informed of intended changes before they are implemented, so those clients are prepared. For example, the implementation of quality assurance will place additional burdens on the firm initially (until its members are comfortable with the system), and the marketing of the service must consider this. Most clients will understand that, especially if they know that they should get a better service from the firm in the long term. Therefore, it is important to involve the client and to keep them informed at all times through a suitable communication medium, such a strategy also helps to generate client input and feedback, in line with the philosophy of ownership and partnering. Clients, experienced or otherwise, will have their own perception of what an architectural firm does, just as they will have a perception of what the structural engineer or general contractor does. For many people, the word "architecture" is synonymous with design. As such the architectural firm offering a diverse range of services, either as a one stop shop or as discrete packages, may find that selling their services to clients meets with some resistance, mainly because the service is unfamiliar. Other players in the marketplace will be promoting their own services to clients, at the same time, playing down the influence of the competition.

Therefore, the challenge of promoting a firm's service provision is hard work and requires constant effort. Allinson (1993) has made the point that the complexity of procurement routes and the large number of professionals often faze clients, especially those with no or little experience of building, all offering their services. In a number of interviews (Emmitt 1999), clients expressed a strong desire for a professional firm that could offer a full service, that was not contractor led, a single point of communication with full responsibility for design, cost, and delivery. They were concerned about the quality and cost of both the building and the service. The demand appears to be there, the challenge for the design led professional service firm is to raise the awareness of the client to their service provision through the use of a well managed promotion strategy. This is especially so for professional service firms that is offering services traditionally seen to lie outside their professional domain. A good example is being architectural practices that actually manage the construction of the building on site, thus, replacing the general contractor. The case study presented below summarises the 
changing profile and service delivery of an architectural practice and looks at some of the challenges this presents in marketing its "unfamiliar” services.

\section{About the Businesses}

At the start of the observation period, the firm was a steady architectural practice, it neither losing money, nor generating very good profits given its fee income. It had a good reputation with its clients and was regarded as treating and paying its staff well. The business had been running for some years and despite a few managerial changes was unlikely to automatically change to any great extent the way it went about its business. Although the directors of the firm have different recollections of what caused them to change the way the firm was managed, they were unanimous in their view that a number of key factors influenced their thinking at the time.

First, it was a couple of repeat clients, who, whilst relatively satisfied with the service they were getting from the firm, were constantly complaining and requesting improvements so much so that they were described as "demanding clients" and the firm found it was very difficult to make a profit from their commissions due to the extra work required. In particular, clients were looking for accountability and single point responsibility with quality and value for money.

Second, it was an interest in quality assurance and its application to a design office, which at the time was seen as a major driver for change and one way of helping to deliver a better service?

Third, it was the economic recession at the start of the 1990s and an increase in competition from other, management orientated, players in the market.

The firm's business plans were simple, yet ambitious:

- Start providing project management services: to retain the client link, to dictate the project culture and to deliver a quality design;

- Implement a quality assurance system: to provide the framework for quality work and to deliver a quality service;

- Build the firm's own designs: to deliver a quality product.

All these three plans' aims could be described as business innovations since they were all relatively unusual at the time. Architectural firms had not marketed project management services particularly well. Other management-orientated firms had started to seize this important link with the client, and effectively push the architect into more of a consultant, rather than team leader, role. Quality assurance had not, and at the time of writing this paper has still not, been adopted with any enthusiasm by the majority of architectural practices, so the firm was in the minority here. Building their own designs was even more radical (Emmitt, 1997a) since at the time when there were only a handful of architectural practices engaged in the physical side of building. All three areas would be unfamiliar to their existing client base, the majority of who had relatively fixed ideas as to who did what in building. It should be recognised that this firm was a long way ahead of the much-publicised reports by Latham (1994) and Egan (1998).

The challenge was to implement these changes using a variety of project management tools whilst maintaining existing clients and attracting a new client base. At the outset, the firm decided to include its existing clients in the organisation's metamorphosis from traditional architectural practice-with a distinct image that everyone was familiar with-into a thoroughly modern, commercially-orientated and market-led design-orientated professional service firm, a rare and unusual organisation. 


\section{Familiar Services to Relatively Familiar Clients: Interpersonal Communication}

At the start of the monitoring period, in early 1990s, the architectural practice had a very rigid marketing policy_all communication with clients was done interpersonally. There was no printed literature other than business cards (which was not that unusual amongst many architectural firms at the time). During the firm's financial year, certain clients were "entertained" by taking them to social events, at which the "soft sell" swung into action. The policy appeared to be successful because many of these clients eventually engaged the firm to provide architectural services. That's to say, there was no formal monitoring procedure so it would be impossible to say how cost-effective such a strategy was. It is also important to recognise that the firm were promoting familiar services to relatively familiar clients, clients who knew what to expect.

With the urge to re-engineer the organisation came the realisation that some form of marketing strategy needed to be put in place since the firm wanted to extend into previously untried territory and needed to attract the attention of new, quite different, clients. The directors felt that some adjustments were needed to their marketing strategy and one of the employees was charged with looking at the existing literature (e.g., Coxe, 1980; Sharp, 1991; RIBA, 1992, and articles in professional journals) and at the policies adopted by other players in the industry, from architects and engineers to contractors and building product manufacturers. The result was presented to the board of directors and after a number of discussions, meetings and adjustments a marketing strategy was agreed upon.

The strategy identified the following action areas, all to be done within the same budget that had previously only dealt with interpersonal communication:

- Re-design the firm's logo and put it on every paper and electronic document leaving the practice;

- Produce a practice brochure;

- Introduce a bi-annual newsletter to keep client informed of changes;

- Monitor and analyse the marketing activity;

- Continue with the interpersonal communication, but more selectively.

The member of staff also recommended that a professional marketing consultancy should be employed to assist with the strategy and make sure it was implemented as professionally as the rest of the firm's service provision. The directors who felt that, as designers, they were capable of doing everything in house did not adopt this. More importantly, it would be cheaper. A cost analysis was made at a later date of the hours spent by various members of staff on marketing activities. On paper, the cost of doing it in house was approximately four times that of employing an external agency. However, the time was, for the most part, taken from slack periods, so it could be argued that it does not cost the firm anything. A degree of caution is needed when analysing such data.

\section{The Marketing Activity}

As the firm started to adjust its staff profile and its service provision, it was also becoming more aware of the messages it was giving off to existing and potential clients. Despite the endeavours of the member of staff charged with managing the marketing activity, the awareness of the importance of communication came through the process of implementing a certified quality assurance (QA) scheme. Fundamental to the effective implementation of QA is clear, concise, and frequent communication, both within the firm and to the firm's customers and suppliers. Although this took a little time to recognise and a few mistakes were made along the 
way, once QA was in place and the firm had adopted a total quality management approach to everything they did, the importance of effective communication became paramount and helped the marketing activity.

The firm has developed into a lean, efficient, and strong service provider without compromising design excellence. Its service provision has grown from traditional architectural services to project management, design management, contract management, and facilities management, available as a complete package or as discrete elements, depending on the client's requirements. Sold separately, or as part of bespoke packages, these services have all contributed to an increase in the firm's fee income. The firm can and does provide an individual service from site identification, design, construction, and maintenance through to re-use. As such, it is ideally placed to deliver not just a quality service but also a quality product, with the scope to make a real impact in terms of delivering environmentally responsible buildings. With the change in focus there was an increased awareness of commercial issues and an increased reliance on the organisation's marketing activity. In addition to careful targeting of potentially profitable clients, the firm spends a lot of time preparing and submitting fee bids (the majority with design), a strategy that has paid off in the long term, and seen as an essential part of the firm's business promotion strategy. Despite its successful transformation, the firm's directors and staff recognise the need for continuous development if they are going to be able to respond to change in the future. Three specific challenges were identified, set alongside a continuing willingness to respond to changes and adjust both its position and culture accordingly.

First is the need to keep a pace of information technology as a means of improving both efficiency and quality of service provision.

Second is the continual problem of knowledge retention, growing the firm's collective experience.

Third is the challenge of promoting the firm's services to clients who may be confused by the number of different procurement routes open to them and the number of competing professionals knocking on their door- the focus of this paper.

The transformation has caused a few problems. There has been resistance from some clients who refused to contribute to the process. Some contractors have removed the firm from their tender list for design and build work because they now compete directly with them for some projects. Some architects have claimed that the firm is being too commercial and no longer a "proper" architectural practice, accusing them of becoming "architects", highlighting the apparent conflict between professional firms and market orientated ones.

So what has the firm become? To answer the question is not easy. On the one hand, the firm is a chartered architectural practice and still refers to itself as such. On the other hand, it is clearly much more than a traditional architectural practice. When marketing its services to clients, the firm uses a whole host of terms to describe more fully what it does, for example, project managers, planning supervisors, and facilities managers are terms used, in addition to that of chartered architects. To a certain extent, this reflects the fragmented nature of the industry and the competitive marketplace, but it also reflects a response to client demands. In many respects, the firm reported here, and others that operate in a similar manner have been doing for some time, what reports by Latham (1994) and Egan (1998) have proposed as the way forward, working closely with client and manufacturers and controlling the supply chain through effective management. The firm has adopted a management and marketing led approach to the business of architecture that has been successful: an approach still not liked by a large number of professionals. However, throughout the firm's metamorphosis, the directors have been careful to retain their professional integrity balancing commercial pressures with professional ethics. The firm now competes just as frequently with surveyors, project managers, and contractors, as it does 
architects for their commissions. In many respects, the firm is carrying out services that were associated with the architect and surveyor role before the rise of the professional institution-architects as true controllers, the old "master builder", and the sole point of responsibility.

\section{Conclusions}

The case study illustrates what can be achieved with limited resources, the challenge of communicating change and also the challenge of communicating a firm's culture, which is it evolving. Transformation takes time and commitment from both staff and directors, and for the case study firm client involvement. New clients need to be educated so that they understand their contribution to the whole building process, which is about ownership and partnering in the pure sense of both words. Marketing has a very important role in raising awareness of the services on offering and reinforcing the message. As demonstrated in this paper, the marketing activity is at the heart of a firm's culture. As such it should not be separated from firm. In preparing this paper there appeared to be a shortage of case study material from which to make comparisons. No doubt this is due to the reluctance of firms to have the process observed and recorded. It is well recognised that firms, professional service firms in particular, like to present an image for public consumption (Ellis \& Cuff, 1989), an image which does not necessarily represent the true picture. There is a need to be a little more open and honest about our individual and collective strengths and weaknesses instead of continually hiding behind the convenient face of professionalism. The challenge for researchers is to get into the firms and see what is really happening.

The case study has highlighted a number of issues familiar to diffusion of innovation researchers. As Rogers (1995) has pointed out, getting a new idea, product, or service adopted is a complex affair. Diffusion literature is well developed in product marketing (Robertson, 1971; Rogers, 1995) and has been applied successfully to the building industry by the author (Emmitt, 1997b), which amongst other things, helped to highlight the complex interactions and temporary networks that may influence the adoption process. The architectural profession was restricted by its own code of conduct from advertising until 1986, and even now, many within the profession feel that advertising is not something professionals do. So, if we view marketing as an innovation for architectural firms, then in line with the empirical evidence provided by over 4,000 independent diffusion studies, we should not be surprised by some of the observations reported in this paper. Some firms will adopt marketing with enthusiasm, others will take longer, while some may never adopt. Assuming firms were prepared to allow researchers access, then this would be an interesting area of research. Carried out with the same professionalism that is reserved for other activities, marketing is an essential part of a professional service firm's competitive strategy and survival in the commercial world of building. The challenge for architectural practices is to recognise that everything the firm does is concerned with communication, with marketing. Then, and perhaps only then, will we see architectural practices competing on equal terms with the more commercially minded players in the industry.

\section{References}

Allinson, K. (1993). The wild card of design: A perspective on architecture in a project management environment. Oxford: Butterworth-Heinemann Ltd..

Coxe, W. (1980). Managing architectural \& engineering practice. New York: John Wiley \& Sons.

Egan, J. (1998). Rethinking construction. London: HMSO.

Ellis, R., \& Cuff, D. (1989). Architects’ people. Oxford: Oxford University Press. 
Emmitt, S. (1997a). Architect and client: Adopting a simple approach to procurement. In C. H. Davidson, \& T. A. Abdel Meguid (Eds.), Procurement: A key to innovation (pp. 185-192). Montreal: CIB Publication 203.

Emmitt, S. (1997b). The diffusion of innovations in the building industry (Ph.D. thesis, University of Manchester, Manchester).

Emmitt, S. (1999). Architectural management in practice: A competitive approach. Longman: Harlow.

Kreps, C. L. (1990). Organisational communication: Theory and practice (2nd ed.). New York: Longman.

Latham, M. (1994). Constructing the team. London: HMSO.

Maister, D. H. (1993). Managing the professional service firm. New York: The Free Press.

Richardson, B. (1996). Marketing for architects and engineers: A new approach. London: E \& FN Spon.

Robertson, T. S. (1971). Innovative behaviour and communication. New York: Holt, Rinehart and Winston, Inc..

Rogers, E. M. (1995). Diffusion of innovations (4th ed.). New York: The Free Press.

Royal Incorporation of Architects in Scotland (RIAS). (1990). The Marchitect. Edinburgh: RIAS.

Royal Institute of British Architects (RIBA). (1992). Strategic study of the profession, phase 1: Strategic overview. London: RIBA Publications.

Ryness, L. C. (1992). Marketing and communication techniques for architects. Harlow: Longman Group (UK) Ltd..

Sharp, D. (1991). The business of architectural practice (2nd ed.). Oxford: BSP Professional Books. 